\title{
TAXATION AND CORPORATE \\ INVESTMENT: THE IMPACT OF THE \\ 1991 SWEDISH TAX REFORM
}

\begin{abstract}
In 1990, the government of Sweden introduced a major tax reform to take effect in 1991. The Swedish system prior to the legislation was so complex that the size and magnitude of the likely effects of the reform on incentives to invest were unknown.

In this paper, we draw on Södersten (1989) and Auerbach and Hassett (1992) and derive an expression for the user cost of capital that captures the essential features of the Swedish tax code both before and after the reform. We estimate the model for investment in equipment and find that the responsiveness of Swedish firms to the user cost is quite similar to that found for the U.S. Finally, we employ our model and estimates to assess the effects of the 1991 reform. We find that the impact of the reform on investment is likely to have been minor and had little to do with the contemporaneous sharp drop in investment.
\end{abstract}
Alan J. Auerbach
Kevin Hassett
Department of Economics
Board of Governors of the
Jan Södersten
549 Evans Hall Federal Reserve System
University of California 20th \& Constitution, NW
Department of Economics Uppsala University
Box 513
Berkeley, CA 94720-3880 and NBER
Washington, DC 20551
S-751 20 Uppsala
SWEDEN 
NBER WORKING PAPER SERIES

TAXATION AND CORPORATE

INVESTMENT: THE IMPACT OF THE

1991 SWEDISH TAX REFORM

\author{
Alan J. Auerbach \\ Kevin Hassett \\ Jan Södersten
}

Working Paper No. 5189

\author{
NATIONAL BUREAU OF ECONOMIC RESEARCH \\ 1050 Massachusetts Avenue \\ Cambridge, MA 02138 \\ July 1995
}

This paper was prepared for a project evaluating the Swedish tax reform of 1991 and presented to a conference in Uppsala in January, 1995. We appreciate the comments of our discussant, Peter Birch Sørensen, and other conference participants. Financial support of the Swedish Economic Council is gratefully acknowledged. This paper is part of NBER's research program in Public Economics. Any opinions expressed are those of the authors and not those of the Board of Governors of the Federal Reserve System, or National Bureau of Economic Research.

() 1995 by Alan J. Auerbach, Kevin Hassett and Jan Södersten. All rights reserved. Short sections of text, not to exceed two paragraphs, may be quoted without explicit permission provided that full credit, including $(9$ notice, is given to the source. 


\section{Introduction}

In 1990, the government of Sweden introduced a major tax reform to take effect in 1991. Many provisions of the reform affected the tax treatment of business fixed investment. The underlying theme of these provisions -- in common with the contemporaneous tax changes of other countries, such as the U.S. Tax Reform Act of 1986 -- was to broaden the tax base while, simultaneously, lowering the statutory tax rate applied to this base. Thus, the statutory corporate tax rate, which, including the profit sharing tax, had been approximately 57 percent, was reduced to 30 percent. At the same time, many of the innovative incentive provisions that had set the Swedish tax system apart were eliminated, notably the investment fund system described in more detail below, as well as other options for deferring tax through the valuation of inventories and other accounting procedures.

The intent of these changes was to keep the tax burden on corporate investment roughly constant, but reduce the behavioral distortions associated with the various incentive schemes. However, predicting the impact of the tax changes was made more difficult by the lack of consensus regarding the net impact of the pre-1991 system on the user cost of capital and hence investment. This paper's objective is to address both of these questions. We first estimate a model of equipment investment behavior for the pre-1991 period to determine which of several potential "regimes" best described investment behavior. Based on our findings, we derive theoretical predictions of the impact that the tax changes ought to have had, and discuss the role of these and other factors in the weak investment performance of the early 1990s.

Our analysis begins with a presentation of a model of investment behavior and the tax rules that affect it. 


\section{The Model}

We begin by presenting the model of firm investment behavior that provides the basis for our empirical estimates. The model and its notation follow closely the development in Södersten (1989), which can be consulted for further details of the derivation. We deviate from that paper's model in the following respects. For simplicity, we assume that the relative price of capital goods equals 1 and, rather than assuming a given debt-capital ratio, take the debt-value ratio as given. ${ }^{\prime}$ Finally, as discussed further below, we take account of the fact that investment may also receive an investment grant, with the size of the grant depending on whether the investment is financed with withdrawals from investment funds.

We consider the behavior of a profit-maximizing, price-taking firm whose production is described by a concave function $\mathrm{F}(\cdot)$ of a single input, homogeneous capital. which is denoted $\mathrm{K}_{\mathrm{t}}$ at time t. Capital depreciates exponentially at rate $\delta$. The tax system has a statutory tax rate $\tau_{\mathrm{t}}$ at time t. Under normal depreciation rules, this capital may be written off at the exponential rate $\gamma$, which, for investment in equipment, equalled 3 over the entire sample period, and receives an investment grant, $\mathrm{k}$. The tax attributes $\tau, \gamma$, and $\mathrm{k}$ alone would give rise to a standard user-costof-capital expression. However, the Swedish tax system has, traditionally, had additional features that alter the firm's incentive to invest. We focus on two here: investment funds and dividend constraints.

'This latter assumption yields simpler expressions for the cost of capital because the valuation of the firm's assets varies by regime. 


\section{Investment Funds}

Until the recent tax reform, firms were permitted to contribute up to a share $f$, of their pretax profits to investment funds, taking a tax deduction for doing so. The constraint on investment fund contributions is:

$$
B_{t} \leq f \Pi
$$

where $\Pi_{t}=P_{t} F\left(K_{t}\right)-\gamma C_{t}$ is the firm's profits before tax at time $t$ (the output price being $P$ ), taking account of the depreciation of the book capital stock $C$.

For each cromn contributed to the firm's investment fund, $b<1$ crowns must be deposited in an interest-free deposit at the Central Bank. Thus, the immediate cash flow consequences of a one-crown investment fund contribution is $\left(\tau_{t}-b\right)$ crowns. When investment funds are withdrawn for investment, or released (the releases, $R$, cannot exceed investment or the current balance of the fund). the deposit b is recovered, so that the out-of-pocket cost of a one-crown investment is (1-b) crowns. ${ }^{2}$ For much of the sample period, firms also received a small investment grant for investment financed by the investment fund. A grant $\mathrm{g}$ per crown of withdrawal has the effect of reducing the firm's net investment cost to (1-b-g). However, such investments cannot also receive depreciation deductions -- they are not added to the book capital stock $\mathrm{C}$-- nor can they receive the normal investment grant, $\mathrm{k}$. Moreover, the government sometimes restricted the use of investment funds, not allowing releases of accumulated amounts.

${ }^{2}$ If $b$ varies over time as contributions are made, withdrawals are made on a FIFO basis, with the refund being based on the value of $b$ that applied upon contribution of the funds withdrawn. 
Generally, the opportunity to reduce taxes through investment fund contributions makes investment funds attractive. However, there are other attributes of the tax system that make more complicated the incentive effects of investment funds.

\section{The Dividend Constraint}

One reason firms might not contribute the maximum amount described in (1) to investment funds is that doing so reduces the cash dividends they can pay. In Sweden, firms can distribute cash dividends, D, only to the extent of their after-tax profits, taking account of investment fund contributions. That is,

$$
D_{t} \leq\left(1-\tau_{\mathrm{t}}\right)\left(\Pi_{\mathrm{l}}-B_{\mathrm{l}}\right)+g_{\mathrm{l}} R_{\mathrm{t}}+k_{t}\left(I_{\mathrm{l}}-R_{\mathrm{l}}\right),
$$

where the last two terms in (2) represent the contribution to after-tax profits of tax credits on investment financed through investment funds and ordinary sources, respectively. Why firms would wish to pay cash dividends at all is itself a conundrum, given that these dividends are taxed at the individual level. However, to the extent that firms can only get cash to shareholders in this way, the firm is in a "trapped equity" regime in which the dividend tax is capitalized and the choice of whether to pay dividends has no net impact on shareholder wealth.

\section{Deriving the Incentive To Invest}

Taking account of the dividend constraint and investment fund rules, we still may derive (details are available upon request) what looks like the standard user cost of capital expression (see, for example, Auerbach and Hassett 1992) which, suppressing subscripts, is: 


$$
F^{\prime}(K)=c=\frac{(1-\Gamma)(r+\delta-\pi)+\dot{\Gamma}}{1-T}
$$

where, as in the standard formulation, $\mathrm{r}$ is a nominal discount rate that takes into account the deductibility of interest, $\pi$ is the inflation rate, $1-\Gamma$ is the effective relative price of investment goods, taking tax provisions into account, and $T^{*}$ is the effective tax rate applying to the quasirents $F^{\prime}\left(K_{t}\right){ }^{3}$ The complexity remains, though, in the expressions for $\Gamma, T^{*}$ and $r$ and their interpretations. Each is based on the Lagrange multipliers of different constraints the firm faces. Which constraints are binding determine the regime under which the firm falls.

In terms of the notation in Södersten (1989), the expressions for $\Gamma, \mathrm{T}^{*}$ and $\mathrm{r}$ are (suppressing subscripts):

$$
\begin{gathered}
\Gamma=\tau+\eta_{1}+\beta_{4}+g \\
T=\tau+\eta_{1} f \\
r=n\left[1-h\left(T \cdot \eta_{2}\right)\right]
\end{gathered}
$$

where $\eta_{1}$ is the multiplier on the constraint that fund contributions not exceed a fraction $f$ of pretax profits, $\beta_{4}$ is the multiplier on the constraint on fund releases, $n$ is the nominal before-tax

${ }^{3}$ Our definition of $\mathrm{T}^{*}$ is slightly different than that in Södersten, but consistent with the derivation presented here. 
cost of funds, $\mathrm{h}$ is the firm's debt-value ratio,$\pi$ is the inflation rate, and $\eta_{2}$ is the multiplier on the constraint that dividends not exceed before-tax accounting profits ${ }^{5}$.

The multiplier $\beta_{4} \neq 0$ if and only if the government constraint on releases, $R=0$, is binding. Because this is in principle an observable government policy, we should know when this is the case. ${ }^{6}$ In all other years, only the multipliers $\eta_{1}$ and $\eta_{2}$ enter into the expression. From inspection of (3) and (4b), it follows that if $\eta_{1}$ also equals zero and investment fund withdrawals receive no investment grant, then the firm's cost of capital is unaffected by the tax system (except possibly through the effect of the interest deduction on $r$ ). The logic is as follows. The term $\eta_{1}$ equals 0 only if firms are not making the maximum permissible contributions to investment funds. Normally, such contributions confer a tax benefit. But if the existing level of contributions to the investment fund reduce measured after-tax profits so much that it is constrained in its ability to pay dividends, additional contributions are of no value. In this case, the corporate tax is simply a tax on distributions that the firm chooses to pay whenever it makes these distributions. As is well known, a tax on distributions has no effect on the cost of capital unless the tax rate is changing over time, i.e., $\tau \neq 0$.

When either of the multipliers $\eta_{1}$ or $\beta_{4}$, or the investment grant for fund withdrawals, $g$, is nonzero, the tax system does affect the user cost of capital through $\Gamma$ and $\mathrm{T}^{*}$, and we must

${ }^{4}$ In our empirical calculations below, we set $h=.5$, a value in line with observed debt-value ratios during the period.

${ }^{5}$ For ease of notation, the multiplier $\eta_{2}$ here corresponds to the one with the same label in Södersten, divided by $(1-\tau)$.

${ }^{6}$ As discussed below, the distinction between release and nonrelease periods is not always clear, empirically. 
determine their values to know the user cost. To do so, we must introduce additional equations and multipliers, with the notation once again taken from Södersten (1989). The following two equations apply in all regimes:

$$
\begin{gathered}
\tau+g-k+\eta_{1}+\eta_{2}+\beta_{3}+\beta_{4}+\lambda_{3}=0 \\
\lambda_{3}(\gamma+r)+\gamma\left(\tau+\eta_{2}+\eta_{1} f\right)-\dot{\lambda}_{3}=0
\end{gathered}
$$

where $\lambda_{3}$ is the shadow price on the book value of the capital stock (equal to minus the present value of tax savings from depreciation allowances when the other multipliers in (5b) are zero) and $\beta_{3}$ is the shadow price on the constraint that withdrawals from investment funds not exceed investment. Normally, this constraint will bind if a firm has a positive balance in the investment fund, since investment-fund-financed investments get a significant share b of their cost paid for from funds at the Central Bank.

Of the four multipliers, $\eta_{1}, \eta_{2}, \beta_{3}$, and $\beta_{4}$, at most two can be nonzero. The first two impose different constraints on investment fund contributions. If the first is binding (the firm would like to invest more in the investment fund), then the second cannot be, for it applies only when the firm is not contributing the maximum amount. If the firm is not permitted any fund releases at all $\left(\beta_{4} \neq 0\right)$ then the constraint that its releases can't exceed investment is not binding $\left(\beta_{3}=0\right)$. If this latter constraint is binding $\left(\beta_{3} \neq 0\right)$, then the firm must be permitted releases $\left(\beta_{4}=0\right)$. Finally, if the firm wishes to invest more than the amount in the investment funds, neither of these constraints will bind. 
Even with these restrictions, equations (5a) and (5b) do not provide us with quite enough information to determine the firm's user cost of capital. Consider the problem at any given time t. Assuming we have solved for the various multipliers at all future dates, $(5 b)$ is an expression in three unknowns, $\lambda_{3}, \eta_{1}$ and $\eta_{2}{ }^{7}$ We also know whether the firm is permitted fund releases, in which case $\beta_{4}=0$, or whether it is not permitted releases, in which case $\beta_{3}=0$. Thus, expression (5a) has four unknowns: those in (5b) plus either $\beta_{3}$ or $\beta_{4}$. This leaves us with two equations in four unknowns, plus the condition that either $\eta_{1}$ or $\eta_{2}$ equals zero. Therefore, we must use additional information to solve the problem. Some important special cases illustrate the use of such information.

\section{Case 1: No Investment Funds}

To establish a benchmark against which to evaluate the impact of investment funds, consider the case in which the investment fund system does not exist. In this case, the maximum contribution fraction is $f=0$, so $T^{*}=\tau$. With no investment fund contributions allowed to reduce book profits, the dividend constraint is less likely to be binding. Let us assume that it does not bind $\left(\eta_{2}=0\right)$. Since investment must exceed investment fund withdrawals, $\beta_{3}=0$. Thus (4a) and (5a) imply that $\Gamma=\tau+\eta_{1}+\beta_{4}+g=\left(-\lambda_{3}\right)+k$. Since $\eta_{2}=f=0$, expression (5b) defines $\left(-\lambda_{3}\right)$ to be the standard present value of tax deductions for depreciation, taken at the tax rate $\tau$. Hence, expression (3) becomes the standard user cost formula, with cash flows taxed, and interest and depreciation deductions taken, at rate $\tau$.

${ }^{7}$ To solve for $\lambda_{j}$. we use a discrete version of $(5 b)$, which is a difference equation relating $\lambda_{3}$ to the concurrent values of $\tau, f, \eta_{1}$ and $\eta_{2}$ and its own value in the next year. 


\section{Case 2: Investment Funds Used for all Investment}

If the firm is not affected by the dividend constraint $\left(\eta_{2}=0 ; \eta_{1} \neq 0\right)$, then we need only know $\eta_{1}$ and $\beta_{4}$ to determine the user cost of capital. If the firm always expects to have sufficient money in the investment fund to finance all investment, then extra crowns contributed to the fund have no value once put in. Assuming, for the moment, that $b<\tau$, the firm will still wish to make maximum contributions. Hence, the multiplier of the maximum constraint on investment fund contributions, $\eta_{1}$, will be nonzero, equal to the immediate cash-flow consequences of making the contribution: the contribution to the central bank, $b$. less the tax deduction, $\tau$. As a result, the tax rate $T^{*}=\tau(1-f)+b f$, and $\Gamma=b+g+\beta_{4}$.

If fund releases are allowed, then $\beta_{4}=0$ and marginal investment is from investment funds, receiving $\Gamma=b+g$ crowns for each crown withdrawn and invested. ${ }^{8}$ If fund releases are not allowed, then we must solve for $\beta_{4}$ to obtain $\Gamma$. Using (5a) and the values of $\eta_{1}$ and $T^{*}$ already derived, we find that $\beta_{4}=k+\left(-\lambda_{3}\right)-(b+g)$, where $\left(-\lambda_{3}\right)$ equals the present value of depreciation allowances taken at current and future values of $T^{*}$. Thus, $\Gamma=k+\left(-\lambda_{3}\right)$, and the user cost expression differs from that of case 1 only to the extent that $T^{*}$ replaces $\tau$.

If the central bank contribution rate, $b$, exceeds $\tau$, as was the case for the last four years in which investment fund contributions were allowed (1985-89), then firms will no longer wish to contribute to the investment fund in this regime. Indeed, they will make no contributions at all,

${ }^{8}$ In this regime, not all withdrawals need come from current-year investment fund contributions. Thus, as discussed above, the value of $b$ appearing in $\Gamma$, say $b^{\prime}$, will be some average of current and past values of $b$. 
behaving precisely as if the maximum contribute rate, $f$, were equal to zero. This has no effect on the previously derived values of $\Gamma$, but does make $T^{*}$ simply equal $\tau$. Thus, for general values of $b$ and $\tau$, firms in this regime face a value of $T^{*}=\min [\tau(1-f)+b f, \tau] .{ }^{9}$

In this "traditional" view of the investment fund system, every dollar of income is taxed at a weighted average of $\tau$ and $b$ according to the shares subjected to federal tax and the implicit investment fund tax. When fund releases are not permitted, marginal investment receives normal investment credits and depreciation allowances, and the incentive to invest is similar to that of the case without investment funds, described above. When releases are allowed, investment is greatly encouraged by the substantial matching component. b. ${ }^{10}$

\section{Case 3: Investment Funds Continually Exhausted}

Suppose, in contrast to the previous case, that although firms always contribute the maximum allowed to investment funds $\left(\eta_{2}=0 ; \eta_{1} \neq 0\right)$, investment always exceeds investment fund balances $\left(\beta_{3}=0\right)$. Then, as long as fund releases are allowed, $\left(\beta_{4}=0\right)$, expressions (5a) and (5b) give us two equations in two unknowns, $\eta_{1}$ and $\lambda_{3}{ }^{11}$ In the special case that the tax system's

${ }^{9}$ This result could be obtained more rigorously by adding an additional constraint to the firm's optimization problem, that fund contributions not be less than zero, with a corresponding Lagrange multiplier, which would be nonzero in this instance.

${ }^{10}$ Taylor (1982) analyzes the impact of investment funds from this perspective, considering the stabilizing effect of the historical timing of fund releases by the government.

"Unlike in case $2, \beta_{4}$-- the shadow price on fund withdrawals -- is likely to be small even when fund withdrawals are restricted. In case 2, withdrawals not permitted today are lost forever, because the firm has excess investment funds available. Here (and in case 4, below), the firm normally carries over no investment funds. Thus, the cost of not being able to make withdrawals is simply the interest lost on the benefits of the deferred withdrawals. As long as the 
parameters are constant over time, the two equations yield an expression for $\eta_{1}$ such that $T^{*}=$ $\tau(1-f)+(\Gamma-g) f$, and $\Gamma=T^{*} z+k$, where $z$ is the present value of depreciation allowances.

The intuition for this "new view" of investment funds is that the firm's marginal investment is not made from investment funds, and so receives the normal depreciation allowances and investment grants of the tax code. However, of each crown of income, only (1-f) is taxed at the statutory rate. The rest, as in the previous example, goes into the investment fund. Here, however, it immediately comes out. Thus, instead of the previous effective tax rate of $b$ on such funds -- the deposit at the Central Bank being forever lost -- the firm gets b right back, along with the extra investment grant, g. But it forgoes the investment grants and depreciation allowances on the inframarginal investment this additional income finances; hence the effective tax rate is $\Gamma-g$ on this portion of income.

\section{Case 4: Binding Dividend Constraint}

In this case, as discussed earlier, the tax system works essentially as a tax on distributions, and thus has no effect (except through the deductibility of interest) on the user cost of capital unless the investment grant system is in effect or the statutory tax rate is changing. We must solve for the value of $\eta_{2}$ in order to determine the value of the interest deduction, which faces an effective tax rate of $\tau+\eta_{2}$ (see (4c)) As we will discuss more fully below, a quite plausible assumption is that investment fund releases are allowed but are insufficient to cover all

restriction on fund withdrawals is expected to be of short duration, this should be relatively insignificant. 
investment. With this assumption, all multipliers except $\eta_{2}$ and $\lambda_{3}$ in expressions (5a) and (5b) equal zero, and, again, we have a system of two equations in two unknowns.

In the special case that the tax system is constant over time, these equations yield the solution $\eta_{2}=(k-g) /(1-z)-\tau$, or $\tau+\eta_{2}=(k-g) /(1-z)$. Thus, when $k=g$, the effect of the interest deduction is nil, and the corporate tax system has no effect whatsoever on the user cost of capital. The intuition is that, for a firm facing the dividend constraint. a crown of interest deductions simply displaces other deductions. ${ }^{12}$

\section{Summary}

Thus far, we have discussed four special regimes, corresponding to the cases in which:

(1) investment funds are not permitted -- the neoclassical, or "no fund" view:

(2) investment fund contributions always are sufficient to fund all investment if releases are permitted -- the "traditional view" of investment funds;

(3) investment fund contributions always are maximized and insufficient to fund all investment -the "new view" of investment funds; and

(4) dividend constraints bind and fund releases are permitted -- what we might label the "no tax" regime, for taxes have almost no impact.

In order to assess the impact of the 1990 tax reform on investment, we must proceed in two steps: first identifying the likely effect of the tax change on the user cost and. second, assessing

${ }^{12}$ When $\mathrm{k} \neq \mathrm{g}$, this shift in the composition of deductions has some impact because it reduces the share of investment financed through investment funds and receiving $\mathrm{g}$, rather than $\mathrm{k}$. 
the likely impact on investment. Unfortunately, in the Swedish case, both steps are unusually difficult. The distinct regimes just presented do not exhaust the possible situations, because firms can switch among regimes from one year to the next. Keeping that in mind, it is nonetheless informative to consider the impact of the reform on the cost of capital in the different possible regimes.

Tables 1-3 contain information on tax parameters and the cost of capital for equipment investment in manufacturing for the period 1984-93. There were differences in some tax provisions across industries. so we choose manufacturing because of its importance. We focus on equipment investment because of prior work (Auerbach and Hassett 1992) suggesting that the user cost model derived here may be inadequate to describe the behavior of investment in business structures. We choose the period 1984-93 to provide a sense of the incentives just before and just after the tax reform.

Table 1 presents three tax variables for this period and industry: the corporate tax rate, $\tau^{13}$, the maximum share of profits that could be contributed to investment funds, $f$, and the share of investment fund contributions that had to be placed in the government fund, $b$. Two other key tax provisions, the investment grants $\mathrm{k}$ and $\mathrm{g}$, were eliminated in 1984 and never reintroduced. The table shows quite clearly the important changes that occurred in the tax reform year of 1991 and the years leading up to it. The corporate tax rate was reduced in both 1989 and 1990 before its large drop in 1991. Investment fund contributed were ended in 1989, and were discouraged by increases in the required deposit fraction, from .5 to .75 in 1985 and .75 to 1 in 1988 .

\footnotetext{
${ }^{13}$ The corporate tax rate gives the combined impact of the base corporate tax rate plus a surcharge known as the "profit-sharing tax" that applied until 1991.
} 
Given the changing tax structure, it is important to consider the role of expectations in forming the user cost of capital. Because it is not clear how much of the significant changes that occurred during this period were anticipated, we present the user costs of capital under two extreme assumptions: that each future year's tax parameters were perfectly anticipated ("perfect foresight") and that, in each year, all tax parameters were expected to stay constant forever ("myopic expectations"). Table 2 presents annual user costs for each of regimes corresponding to the four special case analyzed above, under the assumption of myopic expectations. Table 3 presents the perfect foresight analogues. In each table, we set the nominal required return, $\mathrm{n}$, and the inflation rate. $\pi$, equal to their sample values (.162 and .070 , respectively) in every year, in order to distinguish tax-induced changes in the incentive to invest from other changes. We will consider these other changes below, when examining actual investment behavior. ${ }^{14}$

Each table also provides two sets of estimates for Regime 2. the regime in which investment funds are sufficient to finance all investment. As discussed above, government restrictions on the use of such funds in particular years can have a powerful incentive to invest in this regime. However, the actual impact of these restrictions on fund withdrawals is unclear. In general, unrestricted releases were permitted for equipment during the sample period we study in 1969, 1975-85, and 1991-93. Interestingly, though, the actual pattern of releases varied relatively little between "release" and "nonrelease" periods. This is evident from Figure 1, which shows the share of equipment investment financed with investment fund withdrawals from

${ }^{14}$ Both here and in later calculations, we construct present values of depreciation allowances using a fixed nominal discount rate of 11 percent, roughly its sample value taking account of interest deductibility, rather than allowing this discount rate to vary over time. The effect of this simplification should be minimal. 
1979 through 1992. While the fraction did fall in 1986 when restrictions were imposed, it fell by only a third. It appears that this relative insensitivity of fund withdrawals to apparent restrictions is due largely to a variety of special provisions for releases even during "nonrelease" periods. Thus, it is reasonable to consider two cases for regime 2, the first of which (2a) ignores withdrawal restrictions and the second of which (2b) does not.

Considering first the results for regime 4 , we note that the myopic user cost of capital in Table 2 was constant throughout the period. As indicated above, this user cost is affected by taxes only to the extent that the statutory tax rate varies over time (which is ruled out under myopic expectations) or, through the interest deduction, if the investment grants $\mathrm{k}$ and $\mathrm{g}$ differ. Since both $\mathrm{k}$ and $\mathrm{g}$ equalled zero throughout the period, the myopic user costs for regime 4 are simply those that would hold absent all corporate taxes. The corresponding perfect-foresight user costs deviate from these "no-tax" values only in 1984 and 1990, the years in which anticipated falls in the corporate tax rate make investment and the deferral of dividends attractive.

Turning to regime 1 , the benchmark case, we observe that, prior to the reform, the myopic user cost of capital was slightly above the "no-tax" regime 4 user cost. This user cost fell slightly as a result of the tax reform, to the point where the corporate tax system exerts essentially no impact on the user cost in this regime. The perfect foresight cost of capital is lower for this regime before 1991 because investors, anticipating a steady decline in the corporate tax rate, would have jumped at the opportunity to deduct accelerated depreciation at a high tax rate and pay tax on subsequent cash-flows at a lower rate (Auerbach 1989). 
Comparing the results of regimes 2 and 3 to those previously discussed allows us to measure the effects of the investment fund system under the two views of its effects. As discussed, under the "new" view of investment funds -- regime 3 -- investment funds affect the user cost only through the reduction in the effective tax rate on cash flows, $\mathrm{T}^{*}$. A comparison of the results in columns 3 and 1 indicates that the impact of this difference on the user cost of capital is relatively small during 1984-1988, particularly in the perfect foresight case. The impact vanishes entirely in 1989 , once fund contributions were no longer permitted. It is only in regime 2 , the "traditional" view of investment funds being sufficient to finance all new investment, that the funds lower the user cost significantly.

In regime $2 a$ (for which withdrawal restrictions are ignored), the myopic and perfect foresight assumptions converge, because only current tax parameters matter for the user cost of capital. ${ }^{15}$ As a comparison with regime 4 indicates, the very large investment grant effectively provided by the recovery of government deposits more than offsets the subsequent taxation of cash flows in every year. After 1984, it is no longer optimal for firms in this regime to contribute to investment funds, so their user cost differs from that of regime 1 only to the extent that the initial investment subsidy via fund withdrawals differs in present values from ordinary depreciation allowances and investment grants. This difference rises between 1988 and 1991, as

${ }^{15}$ As discussed earlier, to calculate this regime's user cost, we must know the value of $b$ for those funds being released. Accounting for separate vintages in the optimization process would be intractable, so we simply assume withdrawals are from contributions made over the current and past three years, using a four-year moving average of $b$. For the years 1985 and beyond, when no new fund contributions could be made (after 1988) or would be desired (between 1985 and 1988), we assume any withdrawals would have come from contributions made during 1981-1984, i.e., we use the same value as in the 1984 user cost. 
the declining corporate tax rate reduces the value of ordinary depreciation deductions, but not investment fund withdrawals. However, this regime's very low user cost in the post-reform period is somewhat misleading. Investment fund contributions ended in 1988 at the latest. According to the model for this regime discussed above, contributions actually should have stopped in 1985 , once $b$ rose above $\tau$. Thus, few if any firms are likely to have had past investment fund accumulations large enough to have remained in regime 2 through 1993. Even fewer (presumably, none) would have expected to remain in regime 2 forever. as the calculations for each regime assume.

Considering finally regime $2 \mathrm{~b}$, in which withdrawal restrictions are taken to be fully effective, we see the impact of such restrictions on the user cost of capital. For the myopic case, the user cost rises above that in regime $2 \mathrm{a}$ for the restriction period 1986-90. Because firms do not wish to contribute to investment funds, either, during this period, the firm faces precisely the same user cost as it would in regime 1 , absent the investment fund system. For the perfect foresight case, the user cost dynamics are more complicated. The user cost is reduced in 1985 by the anticipation that withdrawals will cease; it is increased in 1990 by the anticipation that withdrawals will commence. In 1986-88, during which withdrawals are neither permitted nor anticipated, the user cost equals that of regime 1.

Before proceeding to the estimation, it is worth noting that the effects of the reform are to lower or keep constant the user cost of capital, within any regime. The reduction is small in regime 3 and nonexistent in regime 4; it is larger in regime 2 but, as indicated, the results for regime 2 may be misleading. as firms are unlikely to have remained in regime 2 until the end of the period. This does not mean, however, the user cost necessarily declined as the result of the 
reform. Firms that were in regime 2 prior to the reform, having worked off their investment fund balances, eventually would have found themselves in regime 3 (or equivalently, regime 1) after the reform. Since firms in regime 2 faced a much lower user cost than firms in any of the other regimes, the effect of this switch would be a net increase in the user cost of capital as a result of the reform. Another possible transition resulting from the tax reform would be from regime 4 to regime 3 , as the removal of some potential tax deductions might reduce the number of firms having them in excess supply. However, such a transition has a less significant impact on the user cost. We will return to the question of transitions below.

\section{Estimation}

Given the differences in user costs of capital implied by the regimes presented above, it is important to know which of the regimes are relevant to the behavior of firms. We attempt to shed light on this issue in two steps. First, we explore which of the regimes is most consistent with patterns of tax benefit utilization and investment fund use in tax data from Statistics Sweden, studied by Forsling (1995). Second, we estimate separate investment equations for each regime, and see if user costs from any regime clearly fit the data better.

\section{Evidence from Tax Returns}

In this section, we document that it is likely that most firms were in regime 4 just prior to the tax reform. The first bit of evidence comes from Figure 1, already discussed above, which gives the annual share of investment financed by investment fund withdrawals. As already mentioned, firms managed to make fund withdrawals even in years when they were formally 
restricted. This constitutes an argument against regime $2 \mathrm{~b}$, which, as will be seen below, the investment equation estimates seem to confirm. In addition, though, the figure also shows that withdrawals never accounted for more than a quarter of all investment, which strongly argues against regime $2 \mathrm{a}$ as well, which envisions investment funds as the marginal source of investment finance. ${ }^{16}$ Thus, we are left with regimes 3 and 4 to consider.

If regime 4 holds, then firms are tax-constrained, choosing not to make the maximum investment fund contributions because they already have an excess of tax deductions, given their desired dividend distribution policy. Tax-constrained firms might scale back even further on other deductions, such as those for depreciation and inventory valuation. Without such tax constraints, firms have the incentive to maximize all available deductions. But Figure 2 shows that, in the aggregate, this was not the case. The figure presents four series for the period 197992. As a share of maximum allowed contributions, these series depict depreciation deductions, inventory allowances, investment fund contributions, and the total of these three categories. As the figure shows, firms did not approach the maximum in any year for any series. Depreciation allowances were typically just over 80 percent of their allowed maximum, inventory allowances about 60 percent, and investment fund contributions ranging from just over one third to near zero toward 1989 , when they were no longer permitted. This clearly suggests that the typical firm was not facing a binding constraint on its investment fund contributions, as it would in regime 3

${ }^{16}$ Our conclusions would not be as clear were we considering investment in structures, which also could also be financed with investment fund withdrawals. The fraction of structures financed with fund withdrawals was higher during the period (although always below 50 percent). This is consistent with rational behavior on the part of firms, as the investment grants and depreciation allowances foregone were lower for structures than for equipment. 
(or regime 2) but, rather, that it faced the dividend constraint, i.e., $\eta_{1}=0$ and $\eta_{2} \neq 0$. That is, it argues in favor of regime 4.

Investment Data and Regression Results

We begin our empirical investigation by deriving user costs of capital for each of these regimes, taking account not only of tax factors but also the levels of inflation and interest rates that also appear in the user cost and should influence investment. Next, we estimate investment equations for each of the regimes to see how well each of the four user cost series explains investment. Given the complexity of the general user cost expression for the case in which regime switches occur, we will not attempt in this paper to fit a flexible regime-switching investment model. However, we will consider the impact of regime switches between the preand post-reform periods.

In estimating the investment equation, we include not just the current year's user cost of capital, $c_{t}$, but a weighted average of current and future expected values of $c_{t}$. As shown in Auerbach and Hassett (1992), this specification can be derived by applying a Taylor approximation to a general model under which the firm invests subject to convex adjustment costs. The weights on future costs of capital decline geometrically over time at a rate, which we label $\rho$, that increases as adjustment costs become less significant. As also shown in that paper, the addition of productivity shocks to technology leads to a specification which can be approximated by dividing the cost of capital by the contemporaneous rate of return to capital, which we refer to as $\theta$. That is, we estimate the model: 


$$
\frac{I_{t}}{K_{t-1}}=a+b \sum_{s=t} w_{s-t} E_{t}\left(\frac{c_{s}}{\theta_{s}}\right)
$$

where the weights $\mathrm{w}_{\mathrm{s}-t}=\rho(1+\rho)^{-(s-t+1)}$ sum to one. For ease of interpretation and comparison with the results of other studies, we also normalize $\theta$ to have an average value of one.

Our investment data are available at the two digit level for the period 1969-93. In all, we have data for 25 two-digit industries. To keep from being overwhelmed by parameter estimates, we aggregate these data into major industry groups, including mining, manufacturing. and construction. ${ }^{17}$ Then, we estimate by pooling investment and user cost data for these three industries, constraining the user cost coefficient to be the same across the industries but allowing separate fixed-effect intercepts. Because the parameter $\rho$ was difficult to estimate for some specifications and sample periods (because of the nonlinearity it introduces), we present estimates for the case in which $\rho$ is fixed at .5 , a value representative of those estimated by Auerbach and Hassett (1992) for the U.S. This makes the estimated equation linear. In deriving the forward-looking user cost with weights based on $\rho$, we include the current and next three years' user costs. The equations are estimated using lagged user costs and a trend as instruments.

Table 4 presents estimates for each of the four tax regimes. We consider investment behavior over two sample periods, $1969-90$ and 1969-85. The first of these is determined by our

${ }^{17} \mathrm{We}$ also have data from the "commerce" industry, which accounts for about 15 percent of total investment. We have excluded these data from our estimation because a strong upward trend in this industry's investment series suggests that its behavior is being driven by additional factors not captured by our model, and that the assumptions needed to pool observations from the different industries would not be satisfied. These data are included in the aggregate investment series presented in Figure 3. 
data, given the need for future values of the user cost of capital. The second sample period ends before the transition to the new tax system began. As indicated above, the likelihood of regime switches, particularly from regime 2, are important during the transition period. Given that our specification does not take regime switches into account, it is useful to consider results for the earlier period. In order to keep the table manageable, we report only the coefficient estimates on the user cost variable for each equation. In general, the Durbin-Watson statistics often, but not always, revealed serial correlation.

For the shorter sample period, the user cost coefficients are of a reasonable magnitude, similar to those found for the U.S. in Auerbach and Hassett (1992). The results imply that a one percentage point reduction in the user cost of capital (representing a change that, according to regime, is comparable to an investment grant of 2 to 3 percent), increases the investment-capital ratio by from .26 to .38 percentage points -- a 1.5 to 2.1 percent increase in investment, given the sample average investment-capital ratio of .178 . These findings are also consistent with recent work by Dufwenberg et al (1994), who estimated that the elasticity of manufacturing investment to the user cost for Sweden during the period 1965-90 was -.3. Given our sample average of the investment-capital ratio and the sample average values of the user cost in the different regimes, our implied elasticities are $-.36,-.27,-.30$, and -.30 for regimes $2 \mathrm{a}, 2 \mathrm{~b}, 3$, and 4 , respectively.

However, it is difficult to identify the regime that best characterizes investment behavior. Judging by the magnitude of $t$-statistics, the model fits about equally well for all four regimes. This occurs because there is a high degree of correlation--above 90 percent--in the different regimes' user costs during the pre-reform sample period. Put simply, while tax provisions may have played a role, fluctuations in interest rates and profitability, common to all regimes, were so 
much greater that they swamp the tax differences. Moving to the full sample period allows us to make a somewhat better distinction among regimes, with the data appearing to point away from regime $2 b$, the "traditional view" of investment funds, with binding withdrawal restrictions. This rejection of regime $2 \mathrm{~b}$ could be due to greater variation in tax parameters over the extended sample. However, it might also reflect the fact that, with investment fund contributions discouraged after 1984 , fewer firms were in regime $2 \mathrm{~b}$ during the period 1986-90 than in the earlier sample period.

In summary, while our analysis of tax return data suggested that firms were in regime 4 , the regression analysis suggests that three of the four alternative specifications perform about as well empirically, despite the differences in tax incentives across the regimes.

\section{The Impact of the Tax Reform}

Before discussing the predicted impact of the tax reform of 1990-91 on business investment, it is useful to discuss what actually happened to investment during this period. As Figure 3 shows, investment dropped sharply, beginning in 1990. From 1989 to 1993, the investment-capital ratio dropped by roughly 48 percent!

As discussed above, the changes in the user cost of capital attributable to the tax reform were not large, and should have encouraged investment slightly, except to the extent that the reform might have induced a shift from regime 2 . These relatively small effects on the user cost, combined with the size of the coefficients in Table 4, suggest that the tax reform alone played a relatively minor role in the recent investment collapse. Two other factors influencing investment during the period were the increase in real interest rates and decline in profitability. Each of 
these factors, through its increase in our augmented user cost of capital, predicts a decline in investment.

To determine the relative importance of tax and nontax factors, Table 5 offers measures of the total change in the augmented user cost of capital for tax regimes $2 a, 3$, and 4 , and a breakdown of these changes into tax and nontax factors. ${ }^{18}$ To be consistent with the investment equation estimation procedure. which was based on the forward-looking weighted average of the perfect foresight cost of capital, we present this user cost measure in the table. We choose as a base year 1985, early enough to avoid the effect on this forward-looking user cost of any short-run transition dynamics associated with the tax reform. From 1985 to 1993 , the investment-capital ratio fell by a total of .089 , or roughly 42 percent. The table also shows total changes in the user cost for cases in which firms are assumed to have transited from regime $2 \mathrm{a}$ or regime 4 to regime 3 as a result of the tax change -- a possible effect of the tax reform discussed above.

The table's first column shows (for constant tax regimes) the absolute change in the user cost, holding tax attributes at their pre-reform, 1985 values. As this column shows, the user cost increased by 7.0 percentage points in regime 3 , and 6.2 percentage points in regime 4 , as a result of the decline in profitability and increase in real interest rates. The second column of the table shows the total change in the user cost over the period, taking account of tax changes as well.

${ }^{18} \mathrm{We}$ do not present results for a switch from regime $2 b$ to regime 3 for two reasons. First, this regime was least supported by the regression results in Table 4. Second, the user cost of capital for regime $2 b$ in 1985 was extremely low, because of transition dynamics involving the imposition of withdrawal restrictions in 1986. Hence, the incentive to invest in 1985 was quite atypical of the incentives generally faced by firms in this regime prior to the tax reform. 
The incremental effects of tax changes, within regimes, equal to the differences between the first and second columns within a row, are quite small. Indeed, in regime 4 , there is no effect, because in that regime only expected tax changes and investment grants, both absent here, would exert an effect. In regime 3 , the tax reform actually moderated the rise in the user cost slightly. Even regime switches do not produce a large increase in the user cost. For a firm initially in regime 4 , the user cost increases by a total of 6.7 percentage points, or .5 percentage points more, if the firm moves to regime 3 as a result of the reform; and the hypothetical firm moving from regime 2 to regime 3 experiences only a slightly larger rise in the user cost, 7.5 percentage points.

How well do these user cost changes explain the large drop in investment that occurred? For a coefficient of around -.35 , consistent with our results in Table 4 , they predict a drop of the investment-capital ratio of only about one-quarter of the drop of 8.9 percentage points that actually occurred between 1985 and 1993. It is thus not possible to explain the large drop in investment; and, to the extent that we can explain the investment drop, tax changes over the period play essentially no role.

\section{Conclusion}

The preponderance of evidence suggests that the tax reform likely had little effect. While the regression results do not allow us to tell which regime described behavior best before the tax reform, evidence from the use of allowances during the period offers strong evidence in favor of regime 4 , in which the corporate tax system exerts essentially no effect on investment. To the 
extent that firms were in regime 4 prior to the reform and stayed there, the reform had no effect whatsoever on the incentive to invest.

Our the longer term, firms initially in regime 4 might move to regime 3 , as the elimination of investment funds and other available tax allowances would reduce the probability of the dividend constraint binding. However, such a shift would alter the picture little, as the incentives to invest in regime 3 and regime 4 after the reform differ little. The least favorable picture of the reform would hold for firms initially in regime 2 -- the most favorable regime for firms prior to the reform -- that shift to regime 3 after the reform as their investment fund balances are exhausted. However, even in this case, the rise in the user cost of capital due to the reform itself is very small, and swamped in recent years by the impact of the rise in real interest rates and decline in profitability.

Thus, although it is difficult to tell precisely how the tax system influenced investment before the tax reform, we can conclude with some confidence that the results of the tax reform itself (as opposed to contemporaneous macroeconomic factors) on equipment investment are likely to have been minor. 


\section{References}

Auerbach, Alan J., 1989, "Tax Reform and Adjustment Costs: The Impact on Investment and Market Value," International Economic Review, November, pp. 939-62.

Auerbach, Alan J. and Kevin Hassett, 1992, "Tax Policy and Business Fixed Investment in the United States," Journal of Public Economics, March, pp. 141-70.

Bergström, Villy and Jan Södersten, 1984, "Do Tax Allowances Stimulate Investment?" Scandinavian Journal of Economics 86, June, pp. 244-68.

Dufwenberg, Martin, Heikki Koskenkylä, and Jan Södersten, 1994, "Manufacturing Investment and Taxation in the Nordic Countries," Scandinavian Journal of Economics 96, September, pp. 443-61.

Forsling, Gunnar, 1995, "Utilization of Tax Allowances: A Survey of Swedish Corporate Firms, 1979-93," Tax Reform Evaluation Report, Uppsala, forthcoming.

Södersten, Jan, 1989, "The Investment Funds System Reconsidered," Scandinavian Journal of Economics 91, December, pp. 671-87.

Taylor, John, 1982, "The Swedish Investment Funds System as a Stabilization Policy Rule," Brookings Papers on Economic Activity 13:1, pp. 57-99. 
Table 1

Tax Parameters (Manufacturing), 1984-1993

\begin{tabular}{|c|c|c|c|}
\hline Year & $\begin{array}{c}\text { Corporate Tax Rate } \\
(\tau)\end{array}$ & $\begin{array}{c}\text { Contribution Limit } \\
(f)\end{array}$ & $\begin{array}{c}\text { Fund Deposit Share } \\
(b)\end{array}$ \\
\hline 1984 & .576 & .500 & .500 \\
\hline 1985 & .571 & .500 & .750 \\
\hline 1986 & .571 & .500 & .750 \\
\hline 1987 & .571 & .500 & .750 \\
\hline 1988 & .571 & .500 & 1.000 \\
\hline 1989 & .547 & .000 & NA \\
\hline 1990 & .478 & .000 & NA \\
\hline 1991 & .300 & .000 & NA \\
\hline 1992 & .300 & .000 & NA \\
\hline 1993 & .300 & .000 & NA \\
\hline
\end{tabular}




\section{Table 2}

The Effects of the Tax Reform on the User Cost of Capital

(Myopic Expectations)

\begin{tabular}{|c|c|c|c|c|c|}
\hline Year & Regime 1 & Regime 2a & Regime 2b & Regime 3 & Regime 4 \\
\hline 1984 & 0.239 & 0.193 & 0.193 & 0.227 & 0.222 \\
\hline 1985 & 0.239 & 0.205 & 0.205 & 0.226 & 0.222 \\
\hline 1986 & 0.239 & 0.205 & 0.239 & 0.226 & 0.222 \\
\hline 1987 & 0.239 & 0.205 & 0.239 & 0.226 & 0.222 \\
\hline 1988 & 0.239 & 0.205 & 0.239 & 0.226 & 0.222 \\
\hline 1989 & 0.235 & 0.196 & 0.235 & 0.235 & 0.222 \\
\hline 1990 & 0.228 & 0.176 & 0.228 & 0.228 & 0.222 \\
\hline 1991 & 0.221 & 0.141 & 0.141 & 0.221 & 0.222 \\
\hline 1992 & 0.221 & 0.141 & 0.141 & 0.221 & 0.222 \\
\hline 1993 & 0.221 & 0.141 & 0.141 & 0.221 & 0.222 \\
\hline
\end{tabular}




\section{Table 3}

The Effects of the Tax Reform on the User Cost of Capital

(Perfect Foresight)

\begin{tabular}{|c|c|c|c|c|c|}
\hline Year & Regime 1 & Regime 2a & Regime 2b & Regime 3 & Regime 4 \\
\hline 1984 & 0.226 & 0.193 & 0.193 & 0.223 & 0.210 \\
\hline 1985 & 0.222 & 0.205 & -0.085 & 0.223 & 0.222 \\
\hline 1986 & 0.215 & 0.205 & 0.215 & 0.222 & 0.222 \\
\hline 1987 & 0.206 & 0.205 & 0.206 & 0.221 & 0.222 \\
\hline 1988 & 0.193 & 0.205 & 0.193 & 0.220 & 0.222 \\
\hline 1989 & 0.183 & 0.196 & 0.183 & 0.183 & 0.222 \\
\hline 1990 & 0.188 & 0.176 & 0.726 & 0.188 & -0.119 \\
\hline 1991 & 0.221 & 0.141 & 0.141 & 0.221 & 0.222 \\
\hline 1992 & 0.221 & 0.141 & 0.141 & 0.221 & 0.222 \\
\hline 1993 & 0.221 & 0.141 & 0.141 & 0.221 & 0.222 \\
\hline
\end{tabular}


Table 4

Estimates of the User Cost Model

(t-statistics in parentheses)

\begin{tabular}{|c|c|c|c|c|}
\hline Period & Regime 2a & Regime 2b & Regime 3 & Regime 4 \\
\hline $1969-1985$ & -0.379 & -0.256 & -0.294 & -0.331 \\
& $(-3.67)$ & $(-3.86)$ & $(-3.50)$ & $(-3.67)$ \\
\hline $1969-1990$ & -0.463 & -.114 & -0.304 & -0.339 \\
& $(-4.37)$ & $(-1.87)$ & $(-3.44)$ & $(-4.72)$ \\
\hline
\end{tabular}




\section{Table 5}

Explaining the Change in the User Cost of Capital, 1985-93

\begin{tabular}{|c|c|c|}
\hline 1985 Regime-1993 Regime & Change with Constant Tax & Total Change \\
\hline $3-3$ & 0.070 & 0.063 \\
\hline $4-4$ & 0.062 & 0.062 \\
\hline $4-3$ & NA & 0.067 \\
\hline $2 a-3$ & NA & 0.075 \\
\hline
\end{tabular}


Figure 1

Share of Equipment Investment Finance

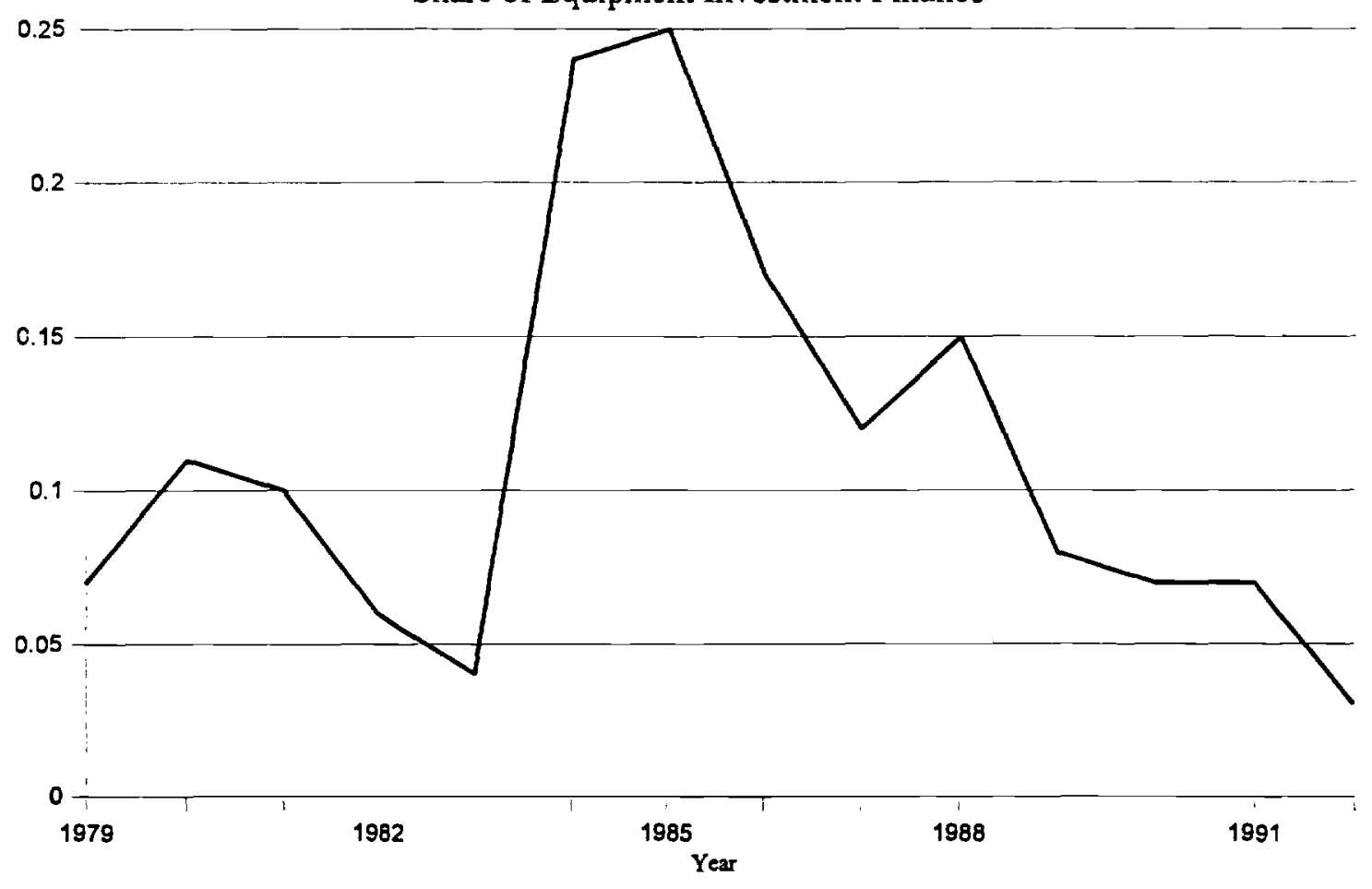




\section{Figure 2}

\section{Use of Tax Allowances}
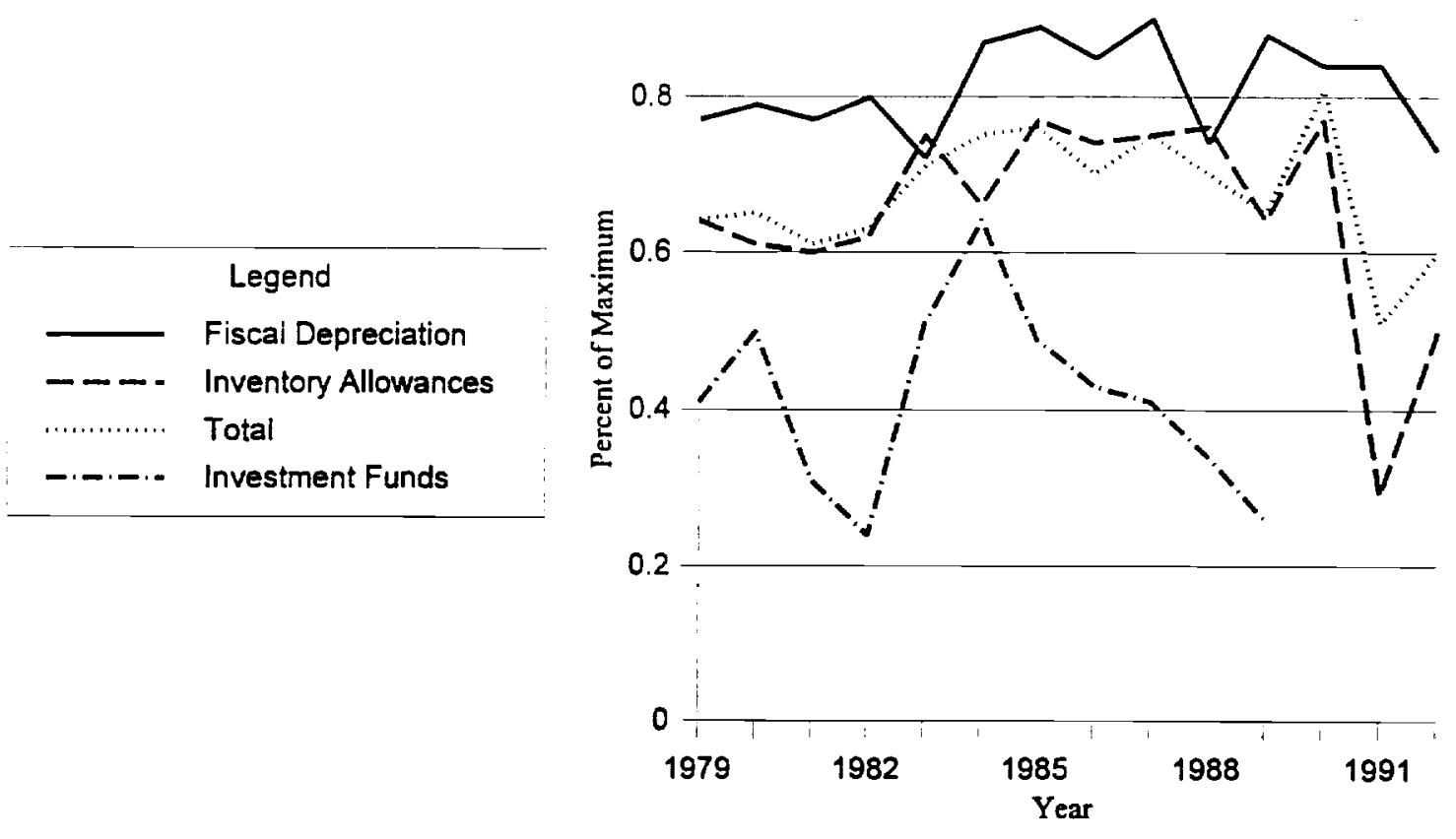


\section{Figure 3}

Investment-Capital Ratios Since 1980

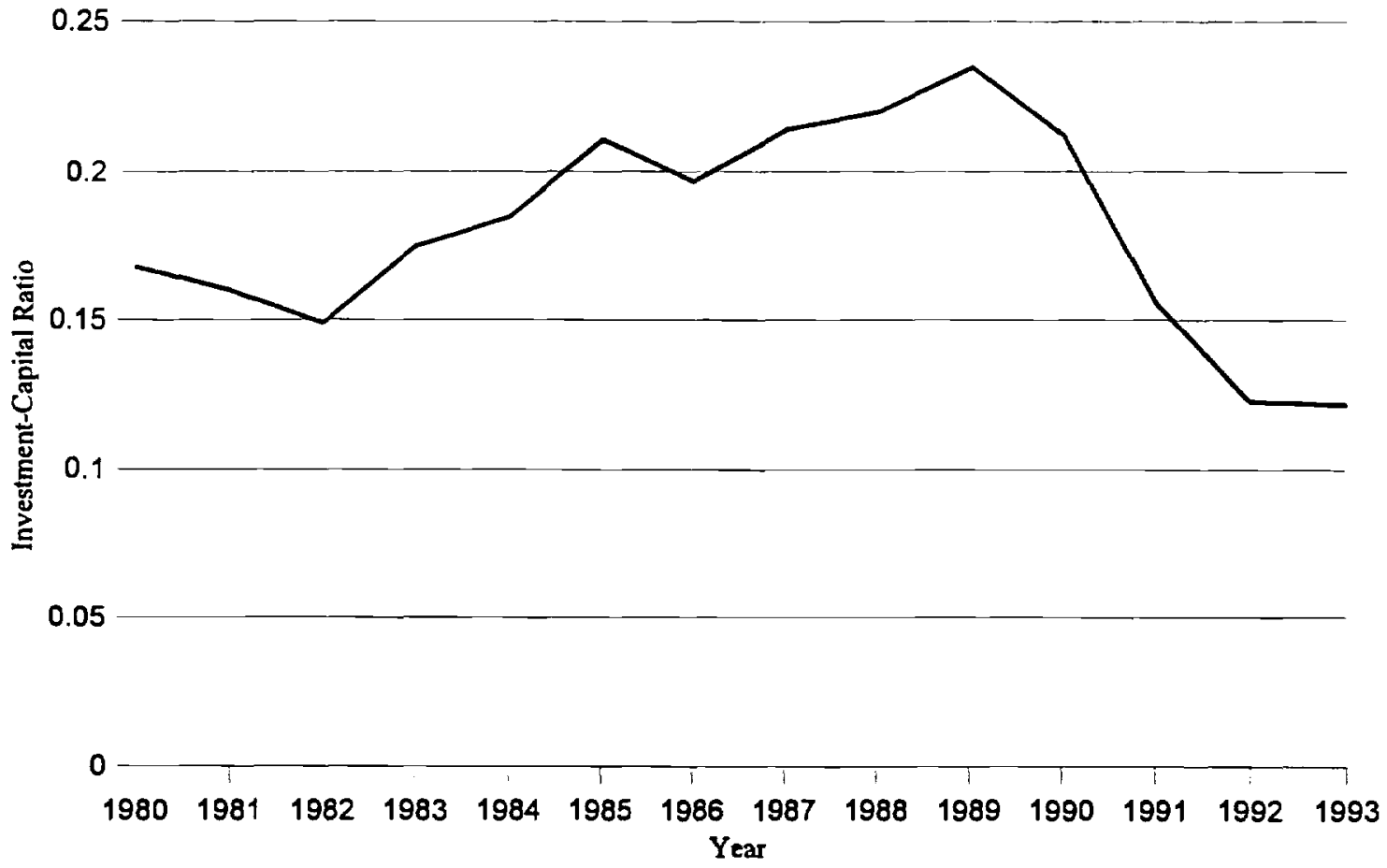

